\title{
Measurement and Evaluation of Industrial Cluster in China
}

\author{
Xiaoyan Wang \\ Business School \\ Suzhou University of Science and Technology \\ Suzhou, China 215009
}

\begin{abstract}
Identification of industrial cluster is an important foundation to quantitatively evaluate the performance of industrial cluster. The identification methods have been used to identify the initial cluster cultivate does not apply to some. In this paper, for the need of strategic assessment of the progress in the areas of the economic transformation, we make comments on these first. Then we set out our views. That is, we decide whether it is industry Cluster with the improved location quotient and the input-output method.
\end{abstract}

Keywords-industrial clusters; location quotient; inputoutput method

\section{INTRODUCTION}

From last century, with the development of industrialization and urbanization, industrial clusters emerge in lots of regions, which had attracted high attention of the economist and government. Industrial cluster is more prevalent in China. In the coastal cities, industrial clusters are easily found. For example, in some areas of Zhejiang, Fujian, Guangzhou, industrial clusters exist in the form of shoe manufacturing industry cluster, leather manufacturing industry cluster, even the button industry cluster. Some local governments build industrial parks to push the development of industry cluster. Industrial cluster plays an important role in local economic development. But what is the mechanism of industrial cluster to push economic development and how to measure the effect of industrial cluster is a problem. Therefore, it is necessary to explore the applicable method to measure and evaluate the effect of industrial cluster.

\section{RELEVANT LITERATURE REVIEW}

The concept of "industry cluster" is advocated by American famous strategic management expert Michael Porter and was widely accepted and cited by many followers. In his research, industry cluster is tightly correlated with competitiveness.

In the "diamond model", Porter conducts theoretical discussion on competiveness of industrial clusters. The model believes that whether a given industry in a region or a country is competitive hinges on four basic factors: factor conditions, demand conditions, corporate strategy, structure and competition, related supporting industries.

Economist and scientist have development several methods to measure industrial cluster. At present, location quotient, input-output method, principal components analysis, multiple clustering method, geographical mapping, and Gini coefficient are commonly used. In this paper, the methods of identifying industrial cluster are systematically discussed and evaluated.

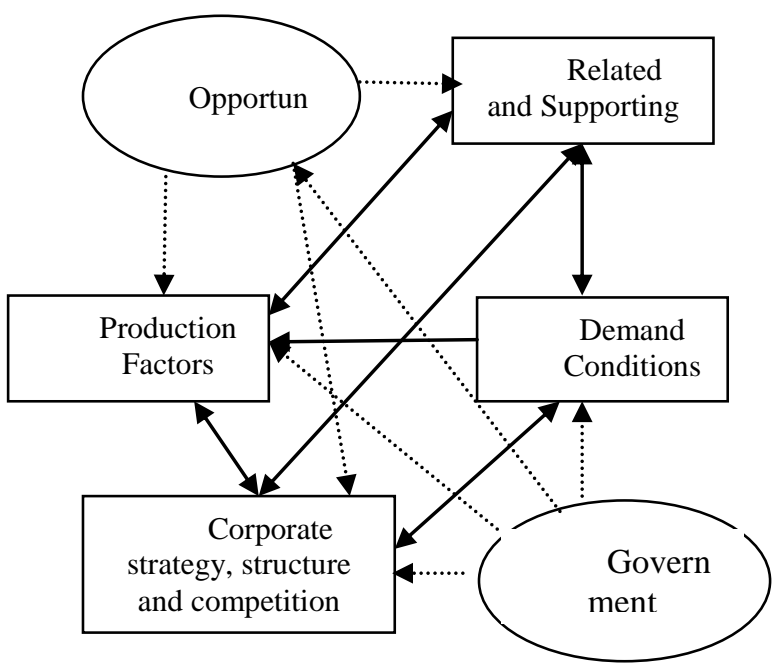

Fig. 1. Porter's Diamond Model.

It is generally acknowledged that location quotient is a qualitative analysis method. It analyses the industrial clusters from some aspects of specialized level and the degree of industry which is at middle range. We can see the trend of industrial cluster when industry is LQ>1. Mao Jiaqiang and Wang Peijia (2007) computed the LQ to identify industrial cluster of Shanxi province. The result indicates that this method is effective. Li Kai, Li Shijie (2004) analyzes the development constitution of manufacturing industry in Shenyang. They computed the LQ and consider the obvious cluster phenomenon in manufacturing industry in Shenyang. Although LQ is known as one of the most important indices for application, there are still some drawbacks. First LQ can't distinguish industrial cluster in the initial period because of $L Q<1$.Second, industrial park is popularly existed in many areas. More and more enterprises enter industrial parks and for the sake of policy support and investment promotion, the scale of industrial cluster. But the number of affiliated companies is very small. It looks like the formation of industrial cluster superficial; however it is not the fact as shown in "Fig. 1".

Input-output analysis, cluster analysis and graph theory are qualitative methods used. The input-output model uses a matrix representation of a region's economy to predict the effect of changes in one industry on consumers, government and the economy. Wassily Leontief developed this method. Input-output analysis is more suitable for the industry chain. 
When the method is applied in small-scale industry groups, it will achieve better effect. But it is not fit for large-scale industry groups because of complex model. Principal component analysis was put forward by Czamanski which neglect restriction on industry scale. But principal component analysis pays much attention to complement rather than forward-backward relation of industry. So is cluster analysis based on input-output. Graph theory uses mathematical structures to model pairwise relations between objects from an industry group. It is another type of cluster analysis which is not better than cluster analysis.

Gini coefficient is a well-known method to measure and evaluate industrial cluster. Wu Xuehua and Yang Huixin (2004) analyzed 20 manufacturing industries with gini coefficient and Herfindahl-Hirschman index. Wang Mingfa (2008) used gini coefficient to identify the industrial clusters of Zhejiang province. The method is especially suitable for mid-small enterprises cluster which is improved by many scholars.

In next section, we will apply two steps to measure the industrial cluster. In the model, we will assemble enterprises, intermediary components and employers will be assembled and correlated in an industry group. Moreover, factors like regional environment will also be considered. Therefore we combine several methods comprehensively to measure it.

\section{Method Used to MeAsure AND Evaluate INDUSTRIAL CLUSTERS}

The concept of industrial cluster emphasizes the importance of spatial proximity. According to Porter (1990), a geographical concentration of related industries, including rivals, suppliers and customers can promote efficiency and specialization. And more importantly, the geographical concentration of industries can accelerate innovation, which is crucial to the development of high-tech industries. Spatial proximity makes it easy for information exchange, and competitive cooperation of enterprises, which makes industrial cluster. Therefore, industrial cluster exists in the form of agglomeration geographically.

There are three critical dimensions in the concept of in industrial cluster: the interdependence or linkage, time or stage of development and geography (Feser, 2001).

The industry life cycle theory divides the development into four stages, and the propensities are specific in different stages. That is to say, it is hard to get the evaluation by one step. Moreover, concentration of some new industries is inconspicuous. So, this paper applies a method with two steps to measure the industry cluster. Meanwhile, empirical and comparison studies were made to analyze the stage of industrial cluster.

\section{A. Measurement of Industry Agglomeration}

Location quotient which was first brought forward by $\mathrm{P}$. Haggettis is an efficient way to evaluate the concentration of industries in some region.

The formula for computing location quotients can be written as:

$$
L Q=\left(E_{i j} / \sum_{j} E_{i j}\right) /\left(\sum_{j} E_{i j} / \sum_{i} \sum_{j} E_{i j}\right)
$$

Where $E_{i j}$ implies local influential factor $\mathrm{j}$ in industry $\mathrm{i} ; \sum_{i} E_{i j}$ implies Total local influential factor $\mathrm{j} ; \sum_{j} E_{i j}$ implies reference area influential factor $\mathrm{j}$ in industry $\mathrm{I} ; \sum_{i} \sum_{j} E_{i j}$ implies total reference area influential factor $\mathrm{j}$. Factors that affect the industry include industry output, sales revenue, employment and investment etc. It is generally believed that agglomeration degree in the industry park is higher than that of the national average level. The larger LQ is, the higher level of specialization is. LQ>1 generally suggests that agglomeration degree is high and it is often called an industrial agglomeration.

LQ $<1$ suggests that the industry has a low level of specialization. But LQ is possibly less than 1 when considering that the new industries begin to emerge in many resource-exhausted cities. We can improve this method based on derivative principle. The formula can be expressed as follow:

$$
\Delta L Q=\Delta\left(E_{i j} / \sum_{j} E_{i j}\right) / \Delta\left(\sum_{j} E_{i j} / \sum_{i} \sum_{j} E_{i j}\right)
$$

$\Delta L Q$ indicate the ratio of the variance of local influential factors and the variance of the reference area influential factors. $\Delta L Q>1$ suggests that the industry has a high level of specialization. The larger $\Delta L Q$ is, the higher the increasing rate of influential factors are.

Ellision \& Glaeser(1997) proposed a new index to measure industrial spatial agglomeration. Given there are $\mathrm{N}$ enterprises in an industry district, which divides the district into $\mathrm{M}$ areas in geography. The formula of the industrial spatial cluster is:

$$
\begin{aligned}
\beta & =\frac{G-\left(1-\sum_{i} q_{i}^{2}\right)^{2} H}{\left(1-\sum_{i} q_{i}^{2}\right)^{2}(1-H)} \\
& \frac{\sum_{i=1}^{M}\left(p_{i}-q_{i}\right)^{2}-\left(1-\sum_{i=1}^{M} q_{i}^{2}\right)^{2} \sum_{j=1}^{N} S_{j}^{2}}{\left(1-\sum_{i} q_{i}^{2}\right)\left(1-\sum_{j=1}^{N} S_{j}^{2}\right)} \\
= &
\end{aligned}
$$

Where, $\beta$ denotes spatial cluster index, $p_{i}$ denotes the ratio of employment of the total employment for the industry in district $\mathrm{i}, q_{i}$ denotes the ratio of employment of the total employment for all industries, $s_{j}$ denotes market share for firm j. H stands for Herfindahl index, which is $H=\sum_{j=1}^{N} S_{j}^{2}$, describing firms distribution in the industry based on employment.

This method - concentration index of industrial space- takes firm size and regional difference into account, avoiding the shortcoming of Geni coefficient, while there is no acceptable explanation to the $\mathrm{H}$.

\section{B. Measurement of Industry Relationship}

As usual, we can't measure and evaluate industrial cluster easily because there is concentration phenomenon in district distribution. We should also calculate the relational degree of industry. Input-output analysis is usually used to 
identify economically related industry clusters. We make the following assumption for the method: homogeneity, proportion, relative stability and no-interaction. Input-output depicts inter-industry relation of an economy by coefficient matrix. The concrete steps are as follows:

First, to establish an input-output model:

$$
\left(\begin{array}{ccccc}
x_{11} & x_{12} & \ldots & x_{1 n} & x_{1 n+1} \\
x_{21} & x_{22} & \ldots & x_{2 n} & x_{2 n+1} \\
\cdots & \ldots & \cdots & \ldots & \ldots \\
x_{n 1} & x_{n 2} & \ldots & x_{n n} & x_{n n+1}
\end{array}\right)
$$

$x_{i j}$ denotes the cost of the enterprise $\mathrm{i}$ that was sold to the enterprise $\mathrm{j}$ in industry park $(\mathrm{i}, \mathrm{j}=1,2, \cdots, \mathrm{n}) . x_{i n+1}$ denotes the cost that is sold to enterprise outside industry park by the enterprise $i$ in industry park. $\sum_{j=1}^{n} x_{i j}$ denotes the cost of intermediate goods.

Second, to calculate the relational degree:

$$
\begin{aligned}
& k_{i}=\sum_{j=1}^{n} x_{i j} / \sum_{j=1}^{n+1} x_{i j} \\
& k=\sum_{i=1}^{n}\left(k_{i} / w_{i}\right)
\end{aligned}
$$

$k_{i}$ denotes the relationships between enterprise $\mathrm{i}$ and the related enterprises. $k$ denotes the proportion of enterprise cost in industry. $k>1$ shows that the relationship in the industry is positive.

\section{CONCLUSION}

In this paper, we firstly discuss several commonly identification methods: location quotient, input-output analysis, principal component analysis, cluster analysis and graph theory and so on. On this basement, we have improved the location quotient and identify industrial cluster by the improved location quotient and input-output analysis. We must consider the agglomeration and relation of industry when we identify industrial cluster. This study is at starting stage in China now. There will be new outbreak in this field.

\section{REFERENCES}

[1] Edward W. A methodology for identifying the drivers of industrial clusters the foundation of regional competitive advantage [J].Economic Development Quarterly, 2000, 14(1):65-96

[2] Chris J. B. The economics of industrial clusters and an examination of their performance in Denmark [J].2003, (5):4-26

[3] Zhang Huajian, Zhang Shujing. Research on the criterion of identifying industrial [J].China soft science, 2006, (3): 83-90

[4] Wang Faming. The study on identification of industrial cluster [J].Economic geography, 2008, 28(1): 33-43.

[5] Mao Jiaqiang, Wang Peijia. Analysis of the industrial cluster in Shanxi province based on a location quotient method [J]. Journal of Lanzhou University (Social sciences), 2007, 35(6):134-137.

[6] David. B.A, Maryann. P. F. Innovative clusters and the industry life cycle[J].Review of Industrial Organization , 1996,11 (3):253-273.
[7] Yang Xing-long, Ren Ya-tong. Competitiveness analysis of processing industry cluster of livestock products in inner Mongolia based on "diamond model"[J], Asian Agricultural Research, 2012, 4(12): 13-18. 